\title{
Scabies - \\ A Hypersensitive Subject
}

Caleb H. Creswell, BS and Erik J. Stratman, MD*

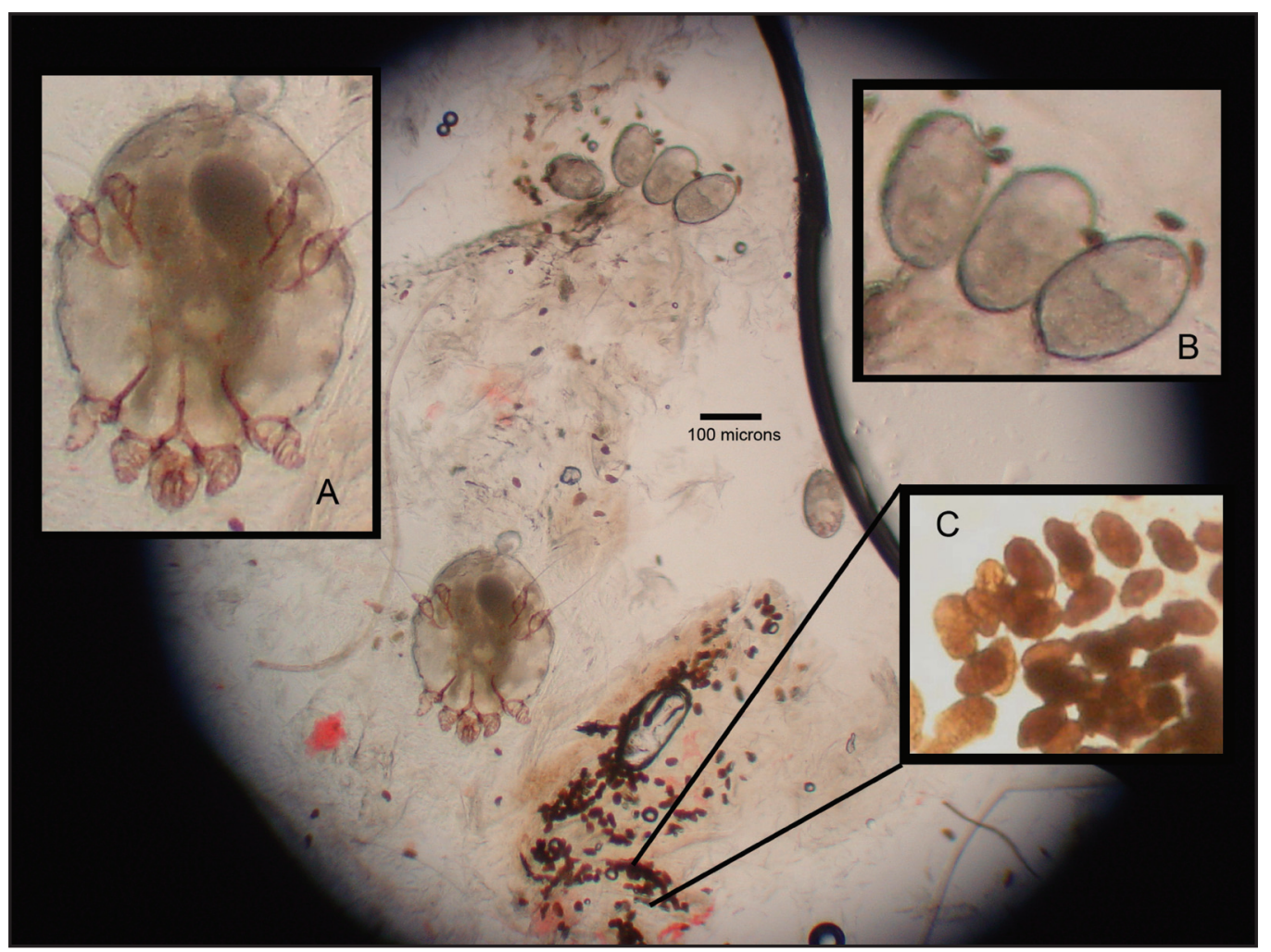

Hypersensitivity reaction to the scabies mite, Sarcoptes scabiei var humanus, can result in an intensely pruritic papular rash. Clinical exam should focus on locating mite burrows, which appear as short, wavy, threadlike scaling lines, sometimes with a small black dot located at one end, representing the burrowing mite. Areas of predilection include the wrists, elbows, umbilicus, axillae, genitals and hands, especially the webspaces.

After locating a burrow, a scabies preparation can be performed by scraping the burrow with a \#I5 scalpel blade dipped in mineral oil and transferring the contents to a glass slide for microscopic examination. The diagnosis can be confirmed with visualization of the scabies mite itself (inset A), the ova of the mite (inset B), or the scybala (feces) of the mite (inset C).

Keywords: Sarcoptes scabiei var humanus, scabies, pruritic papular rash, mite, ova, scybal

\section{Author Affiliations:}

Caleb H. Creswell, BS, University of Wisconsin School of Medicine and Public Health, Madison, Wisconsin 5370 I

*Erik J. Stratman, MD, Department of Dermatology, Marshfield Clinic, 1000 North Oak Avenue, Marshfield, Wisconsin 54449 (Email: stratman.erik@marshfieldclinic.org)

* To whom correspondence should be addressed. humor, and images that provides a portal for new or different views of medicine and research. 